\title{
The mesospheric metal layer topside: a possible connection to meteoroids
}

\author{
J. Höffner ${ }^{1}$ and J. S. Friedman ${ }^{2}$ \\ ${ }^{1}$ Leibniz-Institute of Atmospheric Physics, Kühlungsborn, Germany \\ ${ }^{2}$ National Astronomy and Ionosphere Center, Arecibo Observatory, Arecibo, Puerto Rico \\ Received: 14 October 2003 - Published in Atmos. Chem. Phys. Discuss.: 20 January 2004 \\ Revised: 12 April 2004 - Accepted: 14 April 2004 - Published: 26 May 2004
}

\begin{abstract}
In the past, many studies have been carried out to demonstrate the influence of meteoroids on the atmospheric metal layer, observed roughly in the altitude range $80-105 \mathrm{~km}$. Even with the capability of present day resonance lidars to measure metal densities within single meteor trails, it has been difficult to prove any influence of meteors on the average metal layer. In contrast to approaches taken earlier, we discuss here the seasonal characteristics of potassium, calcium, calcium ion, iron and sodium above $110 \mathrm{~km}$ altitude where the average nocturnal densities are so low that the existence of a baseline level of metal atoms and ions is often overlooked. By comparing simultaneous and commonvolume observations of different metal layers at one location, we demonstrate that despite their different seasonal characteristics at lower altitudes remarkably similar seasonal characteristics are observed at higher altitudes. In addition, a qualitative agreement is also found for potassium at different latitudes. A comparison of metal densities at $113 \mathrm{~km}$ altitude with known meteor showers indicates a strong influence of shower meteoroids on the topside of the metal layers. Simultaneous observations of $\mathrm{K}$ along with $\mathrm{Ca}, \mathrm{Fe}$ and/or $\mathrm{Na}$ permit the calculation of abundance ratios, which at $113 \mathrm{~km}$ altitude are quite similar to values measured in single meteor trails by ground based lidars. Furthermore, the increase in densities throughout summer is strong evidence for the influence of sporadic meteoroids on the high metal layers. This increase correlates well with the seasonal variation of sporadic micrometeor input independent of meteor showers. Given these evidences, we contend that there is a direct influence of ablating meteoroids on the topside of the mesospheric metal layer.
\end{abstract}

Correspondence to: J. Höffner

(hoeffner@iap-kborn.de)

\section{Introduction}

It is generally assumed that the ablation of meteoroids is the only source of metal atoms at the mesopause altitude region. The invention of resonance lidars has made it possible to measure the densities of different metal atoms quantitatively with high vertical and temporal resolution, even inside the trail of an individual meteoroid (Kane and Gardner, 1993; Grime et al., 1999; von Zahn et al., 1999; Drummond et al., 2001, 2002). Consequently, numerous studies have been carried out to link directly certain aspects of metal layers (column density, FWHM, sporadic layers, seasonal changes) to meteor shower activity (Hake et al., 1972; Megie and Blamont, 1977; Gerding et al., 1999; Raizada et al., 2004). In particular, observations during meteor showers such as the prominent Leonids have widely been used to demonstrate the influence of single meteors on the local metal layer (Höffner et al., 1999, 2000; Kruschwitz et al., 2001). From such experiments it has become clear that single meteoroids can, in many instances, have large impacts for a short period on the local metal layers. Simultaneous observations of different metals in the same single meteor trail have shown strong evidence for differential ablation (von Zahn et al., 1999). It was found that more than one metal could be simultaneously observed in only $4 \%$ of observed meteor trails (von Zahn et al., 2002). What fractions of the different metals inside a single meteoroid finally become part of the metal layer is not well known since the ablation process is complex. Proving that meteor showers can change the average properties of metal layers has turned out to be even more difficult. Some authors have found a correlation (Hake et al., 1972; Megie and Blamont, 1977; Uchiumi et al., 1993; Gerding et al., 1999; Höffner et al., 1999) and others not (Chu et al., 2000; Höffner et al., 

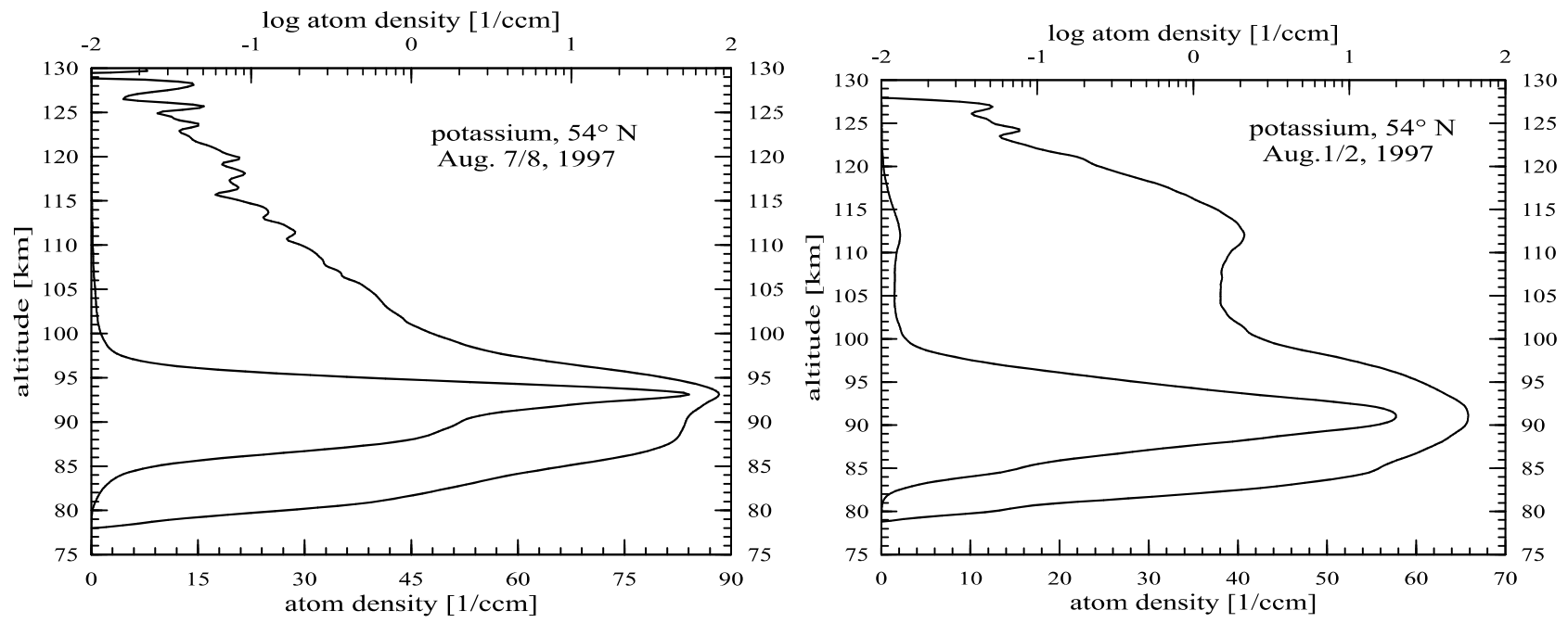

Fig. 1. K-layer of $1 / 2$ and $7 / 8$ August $1997,54^{\circ} \mathrm{N}$ on linear and logarithmic scales. The profiles were obtained during approx. $5 \mathrm{~h}$ of integration. The sensitivity of the lidar allows it to detect free metal atoms at altitudes as high as $125 \mathrm{~km}$ altitude with densities as low as 0.05 atoms $/ \mathrm{cm}^{3}$.

2000). Often such experiments were performed only one time and during the meteor shower itself, and thus lack information about the always present natural variability. Thus, no clear link between variations in the meteoroid flux and metal layer has yet been established.

In contrast to the approaches found in the literature referenced above, we focus our attention on metal and ion layers above $110 \mathrm{~km}$ (what we will refer to as the metal layer topside or high altitude layer). It is widely acknowledged that metal layers, excluding sporadic events, are confined to a region lying between 80 and $105 \mathrm{~km}$ altitude (what we will refer to as the main layer), depending on the season and species. In fact, the density decreases with increasing altitude and becomes undetectable at a certain altitude due to noise, even though, through careful data processing, present day lidars are often able to detect metals and ions at such high altitudes. Janches et al. (2003) have shown that meteoroids observed with incoherent scatter radar are mostly burned up in a distribution from 90 to $120 \mathrm{~km}$ peaking at $107 \mathrm{~km}$. These observations would indicate that a residual population of metal atoms must be maintained in this topside region. At such high altitudes the chemistry is different from the main layer and suffers the least effects from chemical reactions of $\mathrm{O}, \mathrm{O}_{2}, \mathrm{O}_{3}$ or $\mathrm{OH}$ for example. Together with the absence of sporadic layers above say $110 \mathrm{~km}$ altitude and the increased importance of diffusion, the situation is very much different than in the main layer. In this report we present the first results of an investigation of the metal layer topside. We will show that with the chemical reactions mostly out of the way a clear link between metal layers and meteor ablation can be found.

Figure 1 shows two examples of the potassium layer on 78 August (left panel) and on 1-2 August (right panel) 1997 at $54^{\circ} \mathrm{N}$, both integrated over approximately $5 \mathrm{~h}$ of observation. For comparison the same data are shown on linear and logarithmic scales. In the left panel and on the linear scale the layer is only noticeable between 80 and $105 \mathrm{~km}$ altitude. On the logarithmic scale the layer is noticeable as high as $125 \mathrm{~km}$ altitude before the signal vanishes into the background. The minimum detectable density at the topside is approx. 0.05 atoms $/ \mathrm{cm}^{3}$, more than 3 orders of magnitudes lower compared to 85 atoms $/ \mathrm{cm}^{3}$ at $95 \mathrm{~km}$ altitude. Whereas the left panel is an example of very low densities, the right panel, obtained only a few days before, represents an example with much higher densities above $105 \mathrm{~km}$ altitude. Even though the high metal layer is now noticeable on a linear scale it is often overlooked because of the low densities at high altitudes as compared to the main layer down below. Here we will demonstrate that at these high altitudes the seasonal characteristics of various metal layers are significantly different than in the main layer and show correlation to seasonal variability in meteoric input.

\section{Observations}

Between 1996 and 1999 three metal resonance lidars were used to study up to three different metals in the same volume at the site of the Leibniz-Institute of Atmospheric Physics in Kühlungsborn, Germany, $54^{\circ}$ N. One lidar was the containerized and mobile potassium lidar (von Zahn and Höffner, 1996). The second and third lidars were formed by a twin dye laser system, which was able to measure two metals simultaneously in the same field of view (Alpers et al., 1996). These instruments have frequently operated at the same time producing a unique data set with simultaneous common volume 
observations of up to 3 metals or 2 metals plus the $\mathrm{Ca}^{+}$ion. In particular, observations of $\mathrm{K}, \mathrm{Ca}$ and $\mathrm{Ca}^{+}$cover all seasons and have been discussed by Eska et al. (1998) and Gerding et al. (2000). We will also refer to some iron and sodium measurements that do not have complete seasonal coverage but are still valuable. Since 1999 a resonance lidar at the Arecibo Observatory in Arecibo, Puerto Rico, $18^{\circ} \mathrm{N}$, has measured $\mathrm{K}$ with complete seasonal coverage (Friedman et al., 2002, 2003). This allows a comparison of the potassium layer at different latitudes.

\section{Seasonal variations of densities}

As we mentioned before, the metal layer at high altitude is hardly noticeable on a linear scale. Figure 2 reproduces the seasonal structure of 3 metal layers on a logarithmic scale, $\mathrm{K}$ and $\mathrm{Ca}$ from Kühlungsborn (panels a and $\mathrm{b}$, respectively) and $\mathrm{K}$ from Arecibo (panel c). We have smoothed the data with a Hanning Filter of 14 days. The day of year when observations were performed are indicated in the lower part of each panel, with the number of observations on a given day number given by the height of the symbol and right-hand ordinate. The fine dotted vertical lines indicate dates of known meteor shower activity from Table 6-1 of the book of McKinley (1961). The colored dots provide information about different properties of the meteor showers. To account for different noise levels and average densities we have suppressed all data below a certain density level $\left(\mathrm{K}: 0.25\right.$ atoms $/ \mathrm{cm}^{3}$, Ca: 0.5 atoms $/ \mathrm{cm}^{3}$ ). Suppressing the data at these levels helps demonstrate where $\mathrm{K}$ and $\mathrm{Ca}$ behave similarly. As shown in Fig. 1 free metal atoms are indeed often observable at altitudes as high as $130 \mathrm{~km}$ and in some cases can be measured above $140 \mathrm{~km}$ altitude but difficulties in the background subtraction produces artefacts, which we like to avoid.

Despite their different seasonal characteristics in the main layer, all metals behave quite similarly on the topside of the layer where an extension to higher altitudes exists in almost all measurements during summer. With some variability the metal layers are nearly always detectable above $110 \mathrm{~km}$ altitude from May to mid-September. In October a similar extension occurs for a two week period at the mid-latitude site. This has not been observed at Arecibo (panel c). The contour lines above $100 \mathrm{~km}$ clearly indicate the onset of the topside layers when they occur. Below this altitude the contour lines follow more closely the main layer variability.

The overall agreement between $\mathrm{K}$ and $\mathrm{Ca}$ on the layer topside is remarkable because it has been shown that, in the main layer, $\mathrm{K}$ shows a semi-annual cycle with summer and winter maxima (Eska et al., 1998) whereas Ca shows an annual cycle with a winter maximum (Gerding et al., 2000). Main layer seasonal variations are apparent in Fig. 2, as are those for the topside where the seasonal behaviour changes and becomes comparable for all metals, with a summer density maximum. The topside seasonal variations have also been
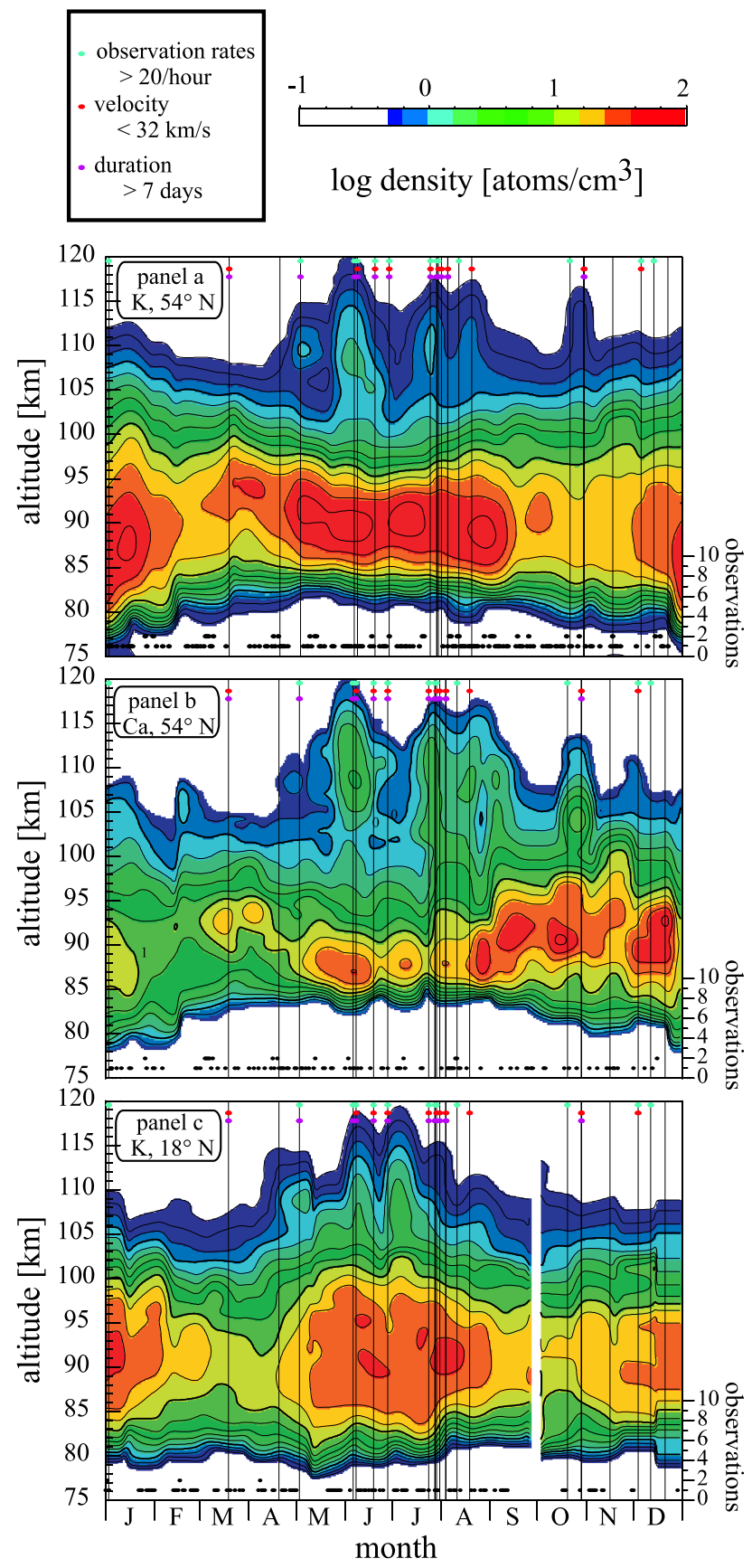

Fig. 2. Metal densities at different locations on logarithmic scales (a) K, Kühlungsborn, $54^{\circ} \mathrm{N}$, (b) Ca, Kühlungsborn, $54^{\circ} \mathrm{N}$, (c) $\mathrm{K}$, Arecibo, $18^{\circ} \mathrm{N}$. For futher explanation see text.

observed for $\mathrm{Ca}^{+}$and denoted for $\mathrm{Fe}$ and $\mathrm{Na}$ observed at $54^{\circ} \mathrm{N}$, though these are not included in Fig. 2.

The observations of $\mathrm{K}$ at different latitudes (panel a and c) show agreement for disparate geographic locations. A closer look shows that the agreement is indeed not as good as between $\mathrm{Ca}$ and $\mathrm{K}$ at a single site. In particular, the extensions of the low latitude $\mathrm{K}$ in July (panel c) are not as strong at mid latitude (panel a). Conversely, the extension in October 


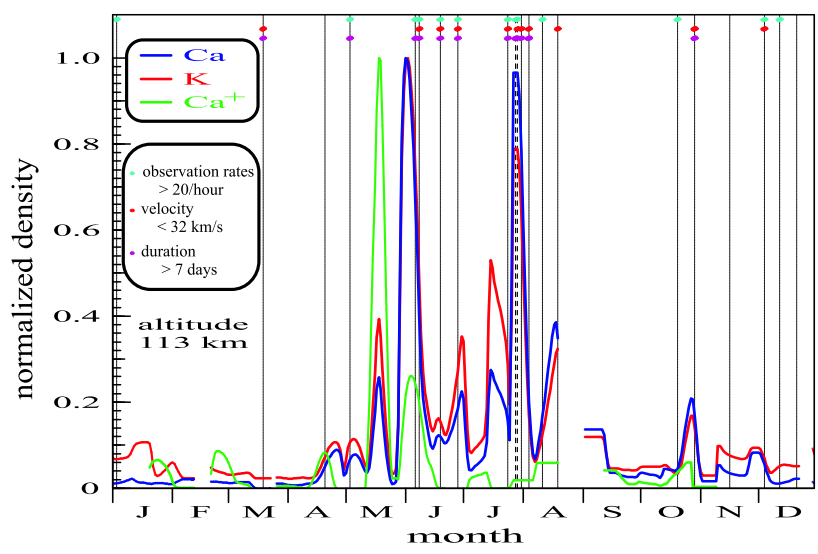

Fig. 3. Seasonal densities of $\mathrm{K}, \mathrm{Ca}$ and $\mathrm{Ca}^{+}$at $54^{\circ} \mathrm{N}$ and $113 \mathrm{~km}$ altitude for simultaneous observations. The data are normalized to account for different absolute densities and smoothed with a 6 day Hanning filter. The fine dotted vertical lines indicate dates of known meteor shower activity from Table 6-1 of the book of McKinley (1961). The colored dots provide information about different properties of the meteor shower.

in panel a is not observed in panel $\mathrm{c}$ but very similar for $\mathrm{Ca}$ (panel b). There are several possible explanations: First, the lack of an extension in October may be an artefact of sparse observations during that season at Arecibo. If the density changes on time scales of a few days or less, then it would be easy to miss just these days when the layer peaks in altitude and/or density. Alternatively, sporadic layers may also influence the overall picture by producing density increases in one layer only, e.g. in $\mathrm{K}$ but not in $\mathrm{Fe}$ or $\mathrm{Ca}^{+}$, as we know from experience. In contrast sporadic neutral layers are uncommon at altitudes above $110 \mathrm{~km}$ as published for $\mathrm{Ca}$ in Gerding et al. (2001). Therefore, the topside layer must be the result of some other source, since at both sites many nights of observations are available as indicated in the lower part of the panels. Extended meteor showers, such as the Perseids and increased summer sporadic meteor activity are both possible contributors to the excess topside metal atoms. Another likely explanation for the lack of a strong correlation between different sites is that large differences occur from year to year. This would be expected if the layers are strongly influenced by meteor showers since the activity of such showers changes from year to year. As mentioned above, the Kühlungsborn observations were made from 1996-1999, while the Arecibo observations were made since 1999. Last, but not least, considerable differences could be caused by the differences in location of the observation sites, and therefore different conditions relative to meteor showers. The famous Leonids shower in November for example is very local, changes greatly from year to year, and has no effect on the layer topside as apparent from panel a, although the shower has been observed by potassium lidar in the altitude range 85 to $100 \mathrm{~km}$ (Höffner et al., 1999). This result seems to indicate that the influence of meteor showers may be overstated as compared with that of sporadic meteoroids. How good the accordance between different metals and $\mathrm{Ca}^{+}$is finally requires simultaneous observations. As mentioned earlier, much $\mathrm{Ca}, \mathrm{Ca}^{+}, \mathrm{K}$ and to some degree $\mathrm{Fe}$ and $\mathrm{Na}$ data have been obtained in Kühlungsborn (Eska et al., 1998; Gerding et al., 2000). These were observed not only at the same site but also very often simultaneously. Similar multi-metal observations are already under way at Arecibo (Tepley et al., 2003).

In the following we focus only on two and three metal observations from a single site. In Fig. 3 we have limited all data to the subset of simultaneous $\mathrm{K}$ and $\mathrm{Ca} / \mathrm{Ca}^{+}$measurements at Kühlungsborn and applied a Hanning filter of 6 days only. Note that we limit the data only to a subset where either $\mathrm{Ca}$ or $\mathrm{Ca}^{+}$is present. A further subset of all three species observed simultaneously would reduce the subset from 101 days to 56 with some larger gaps during the year. We choose to evaluate the densities at $113 \mathrm{~km}$, an altitude at which there is little coupling to the main layers lower down with their different seasonal behaviour. A comparison at much higher altitudes requires a re-evaluation of all calculated densities, since a correct background subtraction becomes more and more important. In some cases metals above $135 \mathrm{~km}$ are present, something that has not been taken into account in the data analysis in the past. Moreover the lower signal strength at higher altitudes introduces larger statistical uncertainties and has to be followed by a statistical analysis. At lower altitudes, the main layer in winter time and the presence of sporadic layers influences the overall picture and would make the discussion more complex. In between, at $113 \mathrm{~km}$ altitude, the typical statistical error of all densities is still of minor importance compared to other possible systematic effects like the mentioned altitude dependent background, slightly different integration periods of the instruments, or a possible influence of sporadic layers in one metal alone. From the statistical point of view the uncertainties in the densities at $113 \mathrm{~km}$ altitude are still small. For the examples of Fig. 1, which represents low and high potassium densities, the statistical errors are in the order of $15 \%$ (left panel) and $1 \%$ (right panel) respectively. For $\mathrm{Ca} / \mathrm{Ca}^{+}$the statistical errors are in the same order of magnitude whereas the stronger signal for $\mathrm{Na} / \mathrm{Fe}$ results on average in even smaller error bars. The surprisingly small statistical errors are caused to a large degree by the long integration times of at least several hours for all measurements and partly by improvements in the technique over that used in the past. The long integration times also reduces effects due to sporadic layers.

From Fig. 3 it becomes immediately obvious that there are indeed fast changes on time scales on the order of a few days or less. Given this high degree of variability, the overall correlation between the densities is remarkable. In particular, all of the major peaks of $\mathrm{K}$ and $\mathrm{Ca}$ can be found one by one and even the relative strengths of the peaks are reproduced to a large degree, if not perfectly. Note that there are 
very few hours of the same-night observations of $\mathrm{K}$ with $\mathrm{Ca}$ and/or $\mathrm{Ca}^{+}$that are not truly simultaneous, though, due to short time layer variability, these few hours may decrease the correlations.

Even $\mathrm{Ca}^{+}$shows maxima at the same time as $\mathrm{K}$. The few exceptions can be attributed to missing data. For example, there are no data available for $\mathrm{Ca}^{+}$during the period end of June where strong maxima exist for $\mathrm{K}$ and $\mathrm{Ca}$. The $\mathrm{Ca}^{+}$ maximum in mid-April is shifted somewhat earlier, which may be caused by different observation dates as well. The strong event in $\mathrm{K}$ and $\mathrm{Ca}$ for the end of July is not observed in the ions because no $\mathrm{Ca}^{+}$observations were performed on the particular night when potassium and calcium peaked. Once again this shows how crucial simultaneous observations are for the intercomparison.

For a better comparison with major meteor showers we marked in Fig. 3 known meteor showers with dotted lines. The occurrence dates of the showers were taken from Table 6-1 of the book of McKinley (1961). Meteor showers vary greatly in the observation rate, shower duration and meteor velocity. The colored dots near the upper ordinate on many of the shower lines indicate thresholds for particular shower properties. It cannot be expected that all showers will be detectable in the same way. Our goal is to demonstrate that at least some of the meteor showers coincide with the topside density enhancements. As discussed before, the visibility of meteor showers varies markedly, and the shower may not be detectable at all on a given year. On the other hand, a topside enhancement in several metals simultaneously should predominantly occur during a shower. There is obviously no shower indicated for the strong peak in midMay, but this simply points to the drawback of this approach, that it assumes that all important showers are known and included in Fig. 3, which is certainly not the case. During 67 March 1997 for example, the two lidars at Kühlungsborn observed a meteor shower (Gerding et al., 1999) that is not included in our list. This shower is not noticeable at $113 \mathrm{~km}$ altitude (Fig. 3) but produced significant effects between 80 and $100 \mathrm{~km}$ altitude. We therefore only state that 7 of the observed maxima are close to major meteor showers, while one strong density maximum in May and a second in July are uncorrelated with major meteor shower activity. The small $\mathrm{K}$ maximum in January appears to be simply related to the morphology of the main layer (Fig. 2a).

The similarity of density maxima with meteor showers demonstrates that there is a link between the topside layers and visible meteor showers. But is this the only explanation? Visible meteor showers represent only a small fraction of the mass influx on the atmosphere consisting of larger particles. Meteor trails, observed by lidar, reflect a similar larger size range in the order of a few millimeters or more (Höffner et al., 1999) with rates in the order of 1 meteor trail per hour during meteor showers. Almost all such events occur at the altitude of the main layer, with a few exceptions at higher altitudes. The absence of such observations is an indication

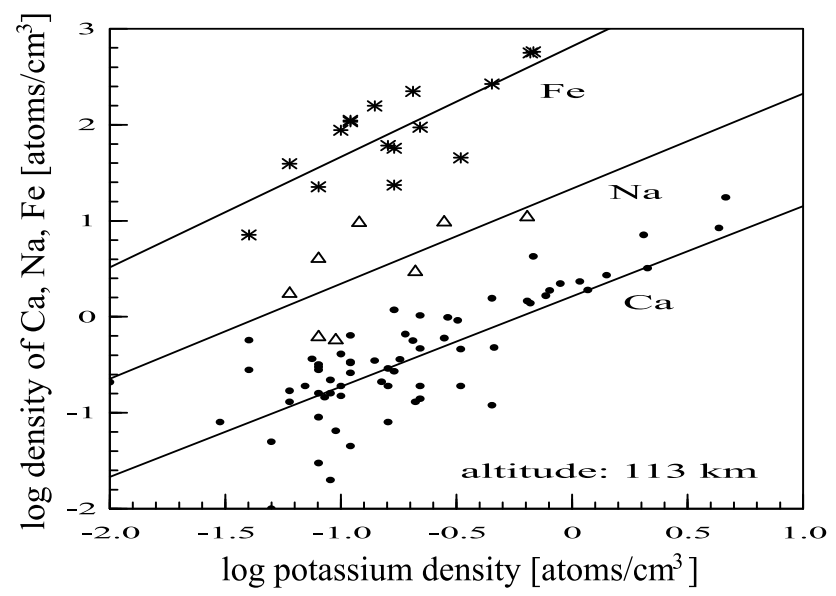

Fig. 4. Shown on a log-log plot are $\mathrm{K}$ densities versus $\mathrm{Ca}, \mathrm{Fe}$ and $\mathrm{Na}$ at $113 \mathrm{~km}$ altitude from simultaneous observations at $54^{\circ} \mathrm{N}$. All regressions have slopes close to one, which implies constant abundance ratios between all elements.

that there is also an influence from smaller particles, which can be observed by radar. The $430 \mathrm{MHz}$ radar at Arecibo detects in the order of 10000 events daily independent of meteor showers (Janches et al., 2003). The largest number of events occurs at $107 \mathrm{~km}$ altitude and the upper boundary is at $120 \mathrm{~km}$, similar to the topside of the layers in Fig. 2. The size range is between 0.5 and $100 \mu \mathrm{m}$, smaller compared to meteor trails observed by lidar. The high altitude layer may reflect a size range more similar to the sporadic meteoroids observed by radar than that for meteor showers. The coincidence of the topside of the metal layers with the upper boundary derived from radar observations, together with the absence of meteor trails observed by lidar give strong support for such a conclusion. Also, the seasonal variation of the incoherent-scatter radar measured micrometeor flux, which is higher in summer than winter (Raizada et al., 2004), provides additional support for such a conclusion. Singer et al. (2004) found that the meteor rates for the meteor radar at $69^{\circ} \mathrm{N}$ varies throughout the year and show a maximum rate in May/June which is also in line with the summer extension. Throughout summer the meteor flux is nearly twice as large as in winter time. Further evidence comes from Figs. 2 and 3. In summer and between the meteor showers the density is still higher as compared to spring or autumn. This permanent summer topside is hardly explained by meteor showers. During the first few weeks of July the densities remain high although no such meteor shower occurs. We will show further evidence for such a possible link in the next section.

\section{Composition}

The simultaneous observations of multiple elements at $54^{\circ} \mathrm{N}$ allow the calculation of the metal abundance ratios at high altitudes. If the layers are a direct product of ablating 
Table 1. Metal abundance ratios derived from simultaneous observations of different metals at $54^{\circ} \mathrm{N}$. The number of simultaneous observations is included in the first column. For comparison, columns marked with an asterisk are copied from von Zahn et al. (2002), Table 7.10. All values with brackets in the last column including $\mathrm{Na}$ are calculated from Table 7.1 of the same authors.

\begin{tabular}{cccc}
\hline Element Ratio & Metal layer $113 \mathrm{~km}$ & Single Meteoroids* & CI meteoroids* \\
\hline $\mathrm{K} / \mathrm{Ca} 66$ nights & $0.57(0.52 \ldots 0.61)$ & $0.23(0.03 \ldots 0.79)$ & 0.0578 \\
$\mathrm{~K} / \mathrm{Fe} 16$ nights & $0.0018(0.0015 \ldots 0.0022)$ & $0.0011(0.00023 \ldots 0.003)$ & 0.0042 \\
$\mathrm{~K} / \mathrm{Na} 8$ nights & $0.046(0.045 \ldots 0.046)$ & - & $(0.062)$ \\
$\mathrm{Fe} / \mathrm{Ca}=(\mathrm{K} / \mathrm{Ca}) /(\mathrm{K} / \mathrm{Fe})$ & $320(280 \ldots 346)$ & $129(33 \ldots 380)$ & 13.9 \\
$\mathrm{Fe} / \mathrm{Na}=(\mathrm{K} / \mathrm{Na}) /(\mathrm{K} / \mathrm{Fe})$ & $26(21 \ldots 30)$ & - & $(14.8)$ \\
$\mathrm{Ca} / \mathrm{Na}=(\mathrm{K} / \mathrm{Na}) /(\mathrm{K} / \mathrm{Ca})$ & $0.081(0.075 \ldots 0.087)$ & - & $(1.07)$ \\
\hline
\end{tabular}

meteoroids then the abundance ratio between two metals should be constant, independent of the season and the apparent density. If only the meteor showers are important then such a constant abundance ratio should only exist during the periods of meteor showers. We have already shown that meteor showers can be identified as density spikes at $113 \mathrm{~km}$ altitude. In the absence of meteor showers the density is typically lower, in particular it is very low in spring and autumn. A constant abundance ratio at low and high densities would therefore indicate an influence of meteor showers and sporadic meteoroids.

In Fig. 4, simultaneously observed densities of $\mathrm{K}$ versus those of $\mathrm{Ca}, \mathrm{Fe}$ and $\mathrm{Na}$ at an altitude of $113 \mathrm{~km}$ are shown on a double-logarithmic scale. What is most striking in Fig. 4 is that all metal densities show a linear relationship to those of $\mathrm{K}$, regardless of their different behaviour at lower altitudes. The slopes of the linear regression are close to one (Ca: 0.94, Fe: 1.15, Na: 0.99). The scatter in the data is several times larger compared to the uncertainties of the individual measurements. This shows that a good agreement only exists when averages are taken over long time scales. For short periods of time larger differences can occur due to sporadic layers or other disturbances. We conclude that all observed metals indeed show a constant abundance ratio as discussed before. Moreover the linear regression also fits the data at very low densities, which represent the permanent topside discussed at the end of Sect. 3. Therefore meteor showers cannot explain all that we have observed. Between such showers the abundance ratios remain constant and still show signs of ablating meteoroids. Because of the similarity to the aforementioned radar observations it is reasonable to believe that the permanent topside is produced by sporadic meteoroids and reflects a smaller size range than observed during meteor showers.

In Table 1 we summarize the metal abundance ratios taken from the regression at different $\mathrm{K}$ densities where inevitable measurement errors that occur for low densities are negligible. The values in brackets are obtained at $\mathrm{K}$ densities of 0.1 and $1 \mathrm{atom} / \mathrm{cm}^{3}$. For comparison, we reprint lidar-measured abundance ratios for meteor trails from Table 7.10 and chon- drite $(\mathrm{CI})$ meteorite abundance ratios from Tables 7.1 and 7.10 of von Zahn et al. (2002). The columns containing results from those tables are marked with asterisks. Von Zahn et al. (2002) include no values for Na. The lidar measured value for $\mathrm{K} / \mathrm{Ca}$, which has the largest number of observations, is approximately 2.5 times larger than found in meteor trails and 10 times larger than found in CI meteorites. Similarly the values for $\mathrm{K} / \mathrm{Fe}$ are only 1.6 times larger and 2.3 times smaller, respectively, and therefore once again in slightly better agreement with the value for meteor trails. A comparison of $\mathrm{K} / \mathrm{Na}$ is only possible with the ratio obtained in CI meteorites. If we consider the poor statistics of $\mathrm{K} / \mathrm{Na}$ observations then the 1.4 times smaller ratio we obtained is remarkably similar With the known ratios it is possible to calculate the ratio of $\mathrm{Fe} / \mathrm{Ca}$ just as $\mathrm{Fe} / \mathrm{Na}$ and $\mathrm{Ca} / \mathrm{Na}$. Fe/Ca is again larger by approximately 2.5 compared to single meteor trails but 23 times larger than in CI meteorites. A similar large difference is found for $\mathrm{Ca} / \mathrm{Na}$ with a 13 times smaller value compared to $\mathrm{CI}$ meteorites. Altogether, keeping in mind that the values could be totally different to the metal abundance ratios found in single meteor trails or CI meteorites, the consistency and fit of our values is remarkable. The agreement is closer for the case of single meteor trails, particularly those of $\mathrm{K} / \mathrm{Ca}$ and $\mathrm{Fe} / \mathrm{Ca}$, which are more than an order of magnitude different than found in CI meteorites but on average only 2 times larger than observed in single meteor trails. The largest difference compared to single meteor trails occurs for $\mathrm{Fe} / \mathrm{Ca}$, but with a value of 2.5 this is still in good agreement. In particular, if we take into account that we have only 16 simultaneous observations with Fe densities as low as 10 atoms $/ \mathrm{cm}^{3}$ compared to 1000 times higher peak densities then this is an exceptional achievement. We note that similar $\mathrm{K} / \mathrm{Ca}$ abundance ratios have also been found in the main layer by Raizada et al. (2004).

\section{Conclusions}

The comparison of metal layers at altitudes above $110 \mathrm{~km}$ reveals a remarkably strong correlation between several metals, calcium ions and the seasonal variation of ablating 
meteoric input. Independently of their seasonal characteristics at lower altitudes, all metals observed by us and presented here show an extension of the layers to altitudes $120 \mathrm{~km}$ and above, predominantly during summer. Simultaneous observations at $54^{\circ} \mathrm{N}$ show that the correlation between $\mathrm{K}, \mathrm{Ca}$ and $\mathrm{Ca}^{+}$above $110 \mathrm{~km}$ is remarkable in contrast to their different seasonal characteristics at altitudes below say $105 \mathrm{~km}$. Similar correlations are found in $\mathrm{Na}$ and Fe although these data sets do not cover all seasons. The correlation between K observations obtained at different latitudes shows that this effect is probably global, but due to lack of simultaneous observations at Arecibo and Kühlungsborn we cannot say whether the global effect holds for individual nights (or shorter time periods) or only as an average seasonal effect. In order to determine the degree of correlation, and thus the effect of meteor showers versus the seasonal variation of sporadic meteoroids, simultaneous observations are crucial. The metal abundance ratios of $\mathrm{K}, \mathrm{Ca}, \mathrm{Fe}$ and $\mathrm{Na}$ at $113 \mathrm{~km}$ altitude are on average constant with respect to latitude and time variations, which allows for comparison with the abundance ratios measured by lidar in single meteor trails and CI meteorites. We find that the obtained values are quite close to, and consistent with respect to, the values obtained in single meteor trails, whereas differences of an order of magnitude exist for $\mathrm{K} / \mathrm{Ca}$ and $\mathrm{Fe} / \mathrm{Ca}$ when compared with $\mathrm{CI}$ meteorites. We believe that our findings support a direct link between ablating meteoroids and the topside metal layers. Even though the influence of individual meteor showers dominates the picture, it remains unclear if, on average, meteor showers or sporadic meteoroids are more important for the topside metal layers. Although there are correlations of the topside with meteor showers, there are also periods in which the topside is there in the absence of known showers and caused by other sources. For example, the summer topside corresponds to a period of high sporadic micrometeor activity. Our findings also imply that the influence of sporadic layers, chemistry and other effects on the topside are comparably small on time scales of several days or longer but may be important on shorter time scales.

Acknowledgements. The authors thank the numerous colleagues and students involved in the data collecting process over the years. Our colleagues C. Tepley, S. Raizada, M. Alpers, M. Gerding, V. Eska and C. Fricke-Begemann have supported this work by investing much time in the exhausting work of night time lidar data collection. J. Friedmann and J. Höffner thank S. Raizada, D. Janches, U. von Zahn and M. Gerding for useful discussions. The Arecibo Observatory is operated by Cornell University under a cooperative agreement with the National Science Foundation.

Edited by: J. Plane

\section{References}

Alpers, M., Höffner, J., and von Zahn, U.: Upper atmosphere $\mathrm{Ca}$ and $\mathrm{Ca}^{+}$at mid-latitudes: First simultaneous and commonvolume lidar observations, Geophys. Res. Lett., 23, 567-570, 1996.

Chu, X., Pan, W., Papen, G., Gardner, C. S., Swenson, G., and Jenniskens, P.: Characteristics of Fe ablation trails observed during the 1998 Leonid meteor shower, Geophys. Res. Lett., 27, 18071810, 2000.

Drummond, J. D., Grime, B. W., Gardner, C. S., Liu, A. Z., Chu, X., and Kane, T. J.: Observations of persistent Leonid meteor trails: 1. Advection of the "Diamond Ring", J. Geophys. Res., 106, 21 517-21 524, 2001.

Drummond, J. D., Grime, B. W., Gardner, C. S., Liu, A. Z., Chu, X., Kelley, M. C., Kruschwitz, C., and Kane, T. J.: Observations of persistent Leonid meteor trails 3. The "Glowworm", J. Geophys. Res., 107, (A8), SIA 5-1, doi:10.1029/2001JA000223, 2001.

Eska, V., Höffner, J., and von Zahn, U.: Upper atmosphere potassium layer and its seasonal variations at $54^{\circ}$ N, J. Geophys. Res., 103, 29 207-29 214, 1998.

Friedman, J. S., Collins, S. C., Delgado, R., and Castleberg, P. A.: Mesospheric potassium layer over the Arecibo Observatory, $18.3^{\circ} \mathrm{N}, 66.75^{\circ} \mathrm{W}$, Geophys. Res. Lett., 29, 15-1:15-4, 2002.

Friedman, J. S., Tepley, C. A., Raizada, S., Zhou, Q. H., Hedin, J., and Delgado, R.: Potassium Doppler-resonance lidar for the study of the mesosphere and lower thermosphere at the Arecibo Observatory, J. Atmos. Solar Terr. Phys., 65, 1411-1424, 2003.

Gerding, M., Alpers, M., Höffner, J., and von Zahn, U.: Simultaneous $\mathrm{K}$ and $\mathrm{Ca}$ lidar observations during a meteor shower on March 6/7, 1997, at Kühlungsborn, Germany, J. Geophys. Res., 104, 24 689-24 698, 1999.

Gerding, M., Alpers, M., von Zahn, U., Rollason, R. J., and Plane, J. M. C.: Atmospheric $\mathrm{Ca}$ and $\mathrm{Ca}^{+}$layers: Mid-latitude observation and modelling, J. Geophys. Res., 105, 27 131-27 146, 2000.

Gerding, M., Alpers, M., Höffner, J., and von Zahn, U.: Sporadic $\mathrm{Ca}$ and $\mathrm{Ca}^{+}$layers at mid-latitudes: Simultaneous observations and implications for their formation, Ann. Geophys., 19, 47-58, 2001.

Grime, B. W., Kane, T. J., Collins, S. C., Kelley, M. C., Kruschwitz, C. A., Friedman, J. S., and Tepley, C. A.: Meteor trail advection and dispersion: Preliminary lidar observations, Geophys. Res. Lett., 26, 675-678, 1999.

Hacke Jr., R. D., Arnold, D. E., Jackson, D. W., Evans, W. E., Ficklin, B. P., and Long, R. A.: Dye-laser observations of the nighttime atomic sodium layer, J. Geophys. Res., 77, 6839-6848, 1972.

Höffner, J., von Zahn, U., McNeil, W. J., and Murad, E.: The 1996 Leonid shower as studied with a potassium lidar: Observations and inferred meteoroid sizes, J. Geophys. Res., 104, 2633-2643, 1999.

Höffner, J., Fricke-Begemann, C., and von Zahn, U.: Note on the reaction of the upper atmosphere potassium layer to the 1999 leonid meteor storm, Earth, Moon and Planets, 82-83, 555-564, 2000

Janches, D., Nolan, M. C., Meisel, D. D., Mathews, J. D., Zhou, Q. H., and Moser, D. E.: On the geocentric micrometeor velocity distribution, J. Geophys. Res., 108, (A6), 1222, doi:10.1029/2002JA009789, 2003.

Kane, T. J. and Gardner, C. S.: Lidar observations of meteoric de- 
position of mesospheric metals, Science, 259, 1297-1300, 1993. Kruschwitz, C. A., Kelley, M. C., Gardner, C. S., Swenson, G., Liu, A. Z., Chu, X., Drummond, J. D., Grime, B. W., Armstrong, W. T., Plane, J. M. C., and Jenniskens, P.: Observations of persistent Leonid meteor trails, 2. Photometry and numerical modelling, J. Geophys. Res., 106, (A10), 21 525, (2000JA000174), 2001.

McKinley, D. W. R.: Meteor Science and Engineering, McGrawHill Series in Engineering Sciences, McGraw-Hill, 309, 1961.

Mégie, G. and Blamont, J. E.: Laser soundings of atmospheric sodium interpretation in terms of global atmospheric parameters, Planet. Space Sci., 25, 1093-1109, 1977.

Raizada, S., Tepley, C. A., Janches, D., Friedman, J. S., Zhou, Q., and Mathews, J. D.: Lidar Observations of $\mathrm{Ca}$ and $\mathrm{K}$ metallic layers from Arecibo and comparison with micrometeor sporadic activity, J. Atmos. Solar Terr. Phys., 66, 595-606, 2004.

Singer, W., Weiß, J., and von Zahn, U.: Diurnal and annual variations of meteor rates at the Artic circle, Atmos. Chem. Phys. Discuss., 1-20, 2004.
Tepley, C. A., Raizada, S., Zhou, Q., and Friedman, J. S.: First simultaneous observations of $\mathrm{Ca}^{+}, \mathrm{K}$, and electron density using lidar and incoherent scatter radar at Arecibo, Geophys. Res. Lett., 30, 1009, doi:10.1029/2002GL015927, 2003.

Uchiumi, M., Nagasawa, C., Hirono, M., Fujiwara, M., and Maeda, M.: Sporadic enhancement of the mesospheric sodium during the Perseids meteor shower, J. Geomag. Geoelectr., 45, 393-402, 1993.

von Zahn, U., Gerding, M., Höffner, J., McNeil, W. J., and Murad, $\mathrm{E}$.: $\mathrm{Fe}, \mathrm{Ca}$, and $\mathrm{K}$ atom densities in the trails of Leonids and other meteors: Strong evidence for differential ablation, Meteorit. Planet. Sci., 34, 1017-1027, 1999.

von Zahn, U. and Höffner, J.: Mesopause temperature profiling by potassium lidar, Geophys. Res. Lett., 23, 141-144, 1996.

von Zahn, U., Höffner, J., and McNeil, W. J.: Meteor trails as observed by lidar, in Meteors in the Earth's Atmosphere, edited by Murad, E. and Williams, I. P., Cambridge University Press, 149187, 2002. 